\title{
SISTEMA ALTERNATIVO PARA EXTRAÇÃO DO ÓLEO RESIDUA DO BAGAÇO DE OLIVA VIA SOLVENTE
}

\author{
B. S. VARGAS ${ }^{1}$, L. A. LISSNER ${ }^{1}$ e S. METH ${ }^{1}$ \\ ${ }^{1}$ Universidade Federal do Pampa, Departamento de Engenharia Química \\ E-mail para contato: brunasvargaseq@outlook.com
}

\begin{abstract}
RESUMO - A olivicultura está em ritmo de crescente expansão no Rio Grande do Sul, estado que possui a maior área plantada de olivas do país. O bagaço de oliva gerado na produção de azeite possui um teor residual de óleo, o qual pode ser extraído via solvente. Nesse trabalho foi realizada a extração do óleo residual do bagaço de oliva, utilizando etanol como solvente através do sistema Soxhlet e de um sistema alternativo. O rendimento da extração do óleo do bagaço de oliva via etanol foi maior que o obtido via hexano. O sistema alternativo demonstrou resultados de rendimento menores que o sistema Soxhlet, porém satisfatórios quando deseja-se trabalhar com maiores quantidades de amostra.
\end{abstract}

\section{INTRODUÇÃO}

Com o intuito de diminuir as importações de óleo de oliva e fazer com que o Rio Grande do Sul possa suprir a demanda de mais de 2 milhões de litros do produto comercializados anualmente em supermercados gaúchos, foram lançados projetos de apoio à olivicultura (OLISUL, 2016). Por conseguinte, o Estado possui atualmente 160 produtores espalhados por 55 municípios, 6 indústrias e 11 marcas de azeite de oliva extra virgem (DALBOSCO, 2016), resultando na maior área plantada do Brasil e em ritmo de crescente expansão segundo dados Embrapa.

A produção do azeite de oliva gera como resíduo o bagaço da oliva, obtido pela extração mecânica do óleo, por moinhos cilíndricos ou a martelo. O bagaço contém película e polpa, podendo incluir pequenas quantidades de caroço, um teor elevado de umidade e um teor residual de óleo (BANDINO \& DETTORI, 2002). De acordo com Correia (2009), a extração via solvente é adotada como opção mais eficiente à prensagem para a extração do óleo de grãos oleaginosos, sobretudo com teores não tão elevados de óleo, como o bagaço de oliva.

O solvente adotado universalmente nas indústrias de extração de óleo é o hexano, pois este atende alguns requisitos tais como baixo calor latente de ebulição, ser apolar e dissolver prontamente o óleo. No entanto, o hexano apresenta algumas desvantagens como alta inflamabilidade, explosividade e toxicidade (OETTERER, et al., 2006). Assim, o etanol surge como uma alternativa menos poluente e mais acessível economicamente como solvente a ser empregado na extração de óleos (SUAREZ, 2002).

O método clássico de extração via solvente é realizada com o sistema Soxhlet, instrumento utilizado quando o composto desejado tem uma solubilidade limitada num 
determinado solvente e as impurezas são insolúveis nesse mesmo solvente (BRIÃO, 2016). Entretanto este equipamento suporta uma quantidade pequena de amostra, e assim, o volume de óleo obtido em cada processo é desprezível. Desta maneira, neste trabalho, sugere-se um sistema alternativo ao método clássico de extração de óleo via solvente, em que há a possibilidade de utilizar quantidades maiores de amostras. Objetiva-se comparar o rendimento de óleo obtido entre o sistema alternativo e o sistema Soxhlet e determinar a viabilidade deste sistema.

\section{MATERIAIS E MÉTODOS}

Para obtenção do óleo do bagaço de oliva realizaram-se dois ensaios de extração- sendo eles pelo clássico sistema Soxhlet e pelo sistema alternativo de extração, utilizando como solvente o etanol com grau de pureza de $99,9 \%$.

O primeiro ensaio foi dado pela extração via solvente através do sistema Soxhlet, como mostra a Figura 1. A metodologia empregada obedece a dada por Brião (2016), em que o bagaço de oliva in natura foi seco previamente em estufa durante $2 \mathrm{~h}$ a $60^{\circ} \mathrm{C}$ e, posteriormente, $1 \mathrm{~h}$ a $80^{\circ} \mathrm{C}$ para eliminar a umidade sem promover a degradação do óleo contido na amostra. Utilizou-se $10 \mathrm{~g}$ de amostra seca, sendo realizados 5 ciclos, para a máxima extração. $\mathrm{O}$ solvente etanol foi recuperado por destilação em evaporador rotativo, podendo ser reutilizado.

Figura 1 - Sistema Soxhlet (a), bagaço de oliva seco (b), evaporador rotativo (c)

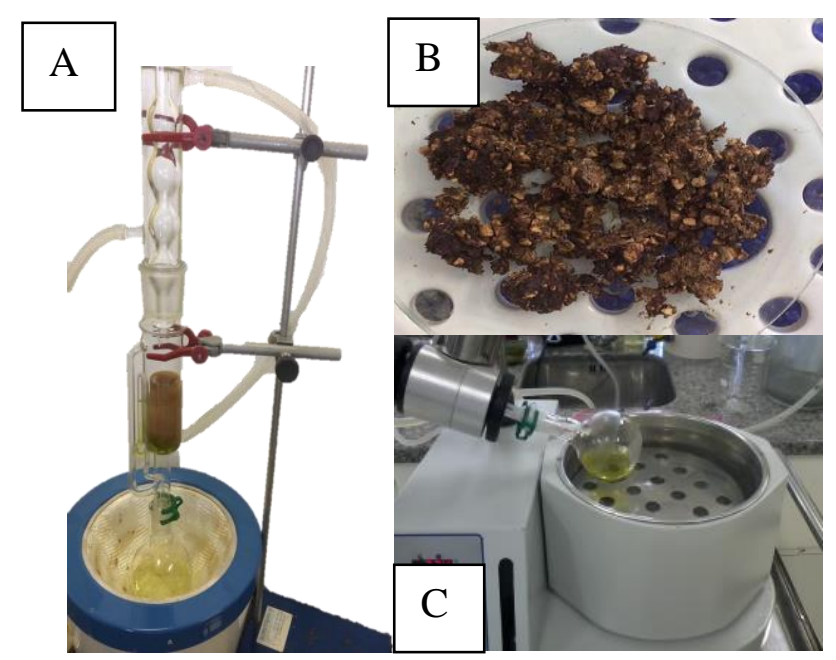

O segundo ensaio foi realizado através de um sistema alternativo de extração ilustrado pela Figura 2, em que $300 \mathrm{~g}$ de amostra seca de bagaço de oliva foram colocados em aquecimento juntamente com o solvente durante $30 \mathrm{~min}$. $\mathrm{O}$ balão que armazenava o conjunto amostra-solvente foi conectado a uma coluna de refluxo e aquecido em uma manta térmica. Da mesma maneira que o primeiro ensaio, o etanol foi recuperado por destilação em evaporador rotativo.

Ressalta-se que a matéria-prima utilizada para os ensaios citados anteriormente foram oriundos da mesma safra de cultivo de oliveiras. 
Figura 2 - Sistema alternativo de extração via solvente (a), conjunto amostra-solvente (b), evaporador rotativo (c)

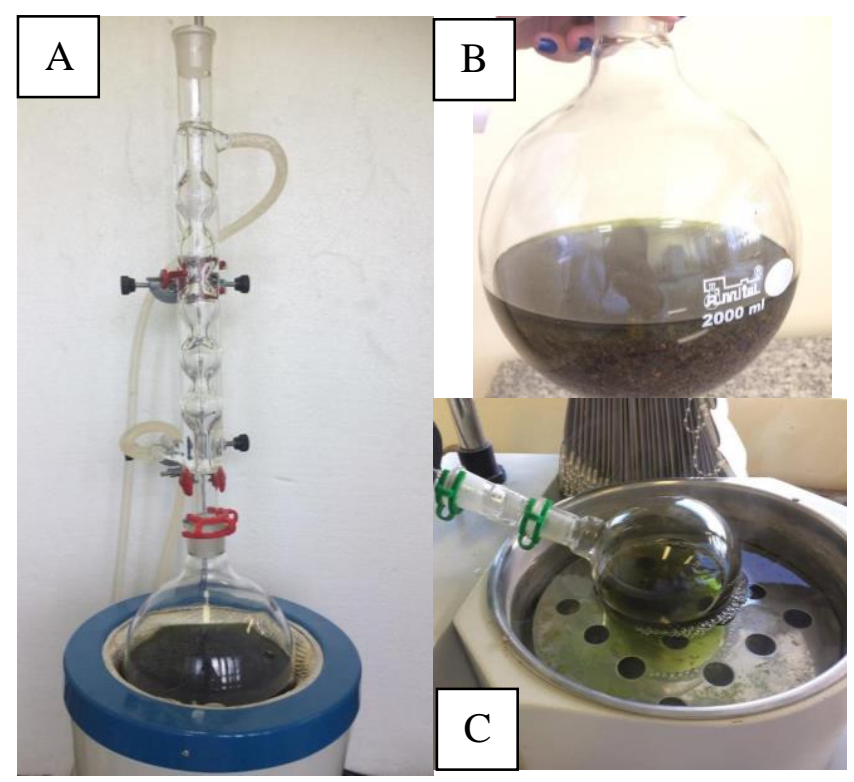

O rendimento foi obtido a partir da razão entre a massa de óleo obtido e a massa de bagaço de oliva seco utilizado no processo.

\section{RESULTADOS E DISCUSSÃO}

O teor percentual de óleo do bagaço de oliva obtido na extração via solventes através do clássico sistema Soxhlet e sistema alternativo é apresentado na Tabela 1. Percebe-se que o teor de óleo extraído via etanol é maior que o dado pela extração com hexano, descrito por Tawarah e Rababah (2013). Além disso, neste trabalho, o percentual de óleo extraído via etanol é ainda maior que o encontrado por Brião (2016) para o mesmo sistema. Destaca-se que em seu trabalho, Brião (2016) utilizou a matéria-prima oriunda do mesmo local de cultivo de oliva utilizado pelo presente trabalho.

A diferença entre os resultados pode ser explicada também pelo fato da matéria-prima ser de origem natural, sujeita a grande variabilidade, mesmo entre cultivares de diferentes safras. Entretanto, ainda sim, é possível indicar a viabilidade e potencial do etanol como um solvente alternativo ao hexano para a extração de óleo tendo em vista os rendimentos obtidos. Ademais, este solvente é menos nocivo ambientalmente, mais acessível economicamente e passível de recuperação após o processo para reuso. 


\section{Congresso Brasileiro de Engenharia Química \\ em Iniciação Científica \\ UFSCar - São Carlos - SP \\ 16 a 19 de Julho de 2017}

Tabela 1 - Teor de óleo extraído do bagaço de oliva

\begin{tabular}{|c|c|c|c|}
\hline \multirow{2}{*}{ Solvente } & \multicolumn{3}{|c|}{ Teor de óleo (\%) } \\
\cline { 2 - 4 } & $\begin{array}{c}\text { Literatura } \\
\text { Soxhlet }\end{array}$ & $\begin{array}{c}\text { Experimental } \\
\text { Soxhlet }\end{array}$ & $\begin{array}{c}\text { Experimental } \\
\text { sistema } \\
\text { alternativo }\end{array}$ \\
\hline n-hexano & 15 a $17^{1}$ & - & - \\
\hline Etanol & $19^{2}$ & $24^{3}$ & $17^{3}$ \\
\hline
\end{tabular}

Fonte: ${ }^{1}$ Tawarah e Rababah (2013), ${ }^{2}$ Brião (2016), ${ }^{3}$ Autora (2017)

O percentual de óleo do bagaço de oliva obtido através do sistema alternativo de extração foi de $17 \%$, ou seja, 70,8\% do teor máximo obtido após 5 ciclos de extração pelo clássico sistema Soxhlet, utilizando etanol como solvente. Observou-se a possibilidade de realizar uma segunda extração com a mesma amostra utilizada no sistema alternativo, o que acarretaria certamente em maior volume de óleo extraído, aumentando assim o rendimento e aproximando-o ainda mais do valor de rendimento obtido por meio do sistema Soxhlet.

Com isto, tem-se que este sistema pode ser uma maneira alternativa viável de extração de óleo quando é necessário trabalhar com maiores quantidades de amostra, pois foi utilizado cerca de $30 \% \mathrm{~m} / \mathrm{m}$ a mais de bagaço de oliva. Embora, a quantidade de solvente empregada no segundo ensaio seja maior, este pode ser recuperado através da destilação por evaporador rotativo.

\section{CONCLUSÃO}

Por meio dos dados obtidos experimentalmente, conclui-se que o etanol pode ser uma alternativa economicamente acessível e correta ambientalmente a ser usado como solvente na extração de óleo de oliva a partir do seu bagaço. Além disso, o sistema alternativo de extração via solvente apresentado nesse trabalho demonstrou-se uma opção viável, com rendimentos satisfatórios. Ademais, este sistema alternativo pode substituir o clássico sistema Soxhlet, para casos em que haja a necessidade de se trabalhar com quantidades maiores de amostras e obtenção de maiores volumes de óleo a cada processo.

Sugere-se para trabalhos futuros a análise da composição química do óleo extraído.

\section{REFERÊNCIAS}

BANDINO, G.; DETTORI, S. Manuale di Olivicoltura. Consorzio Interprovinciale per fla Frutticoltura di Cagliari, Oistano e Nuoro. Cagliari, 2002.

BRIÃO, G. V. Tratamento de efluente da indústria têxtil por bagaço de oliva preparado por tratamento térmico. Trabalho de conclusão de curso. UNIPAMPA, 2016. 
CORREIA, I. M.S. Extração e pirólise do óleo de girassol (Helianthus annus L.) visando a produção de biocombustíveis. Dissertação (Mestrado). UFRN, Natal. 2009.

DALBOSCO, Luciane. $5^{a}$ Abertura Oficial da Colheita de Oliva mostra crescimento do setor. Disponível em: < http://www.rs.gov.br/conteudo/234678/5-abertura-oficial-da-colheitade-oliva-mostra-crescimento-do-setor/termosbusca=*> Acesso em: 22 março 2016.

EMBRAPA. Matérias-primas oleaginosas para a produção de bioquerosene - oportunidades $e$ desafios. Disponível em: <https://www.embrapa.br/busca-de-noticias/Inoticia/3344909/artigo-materias-primas-oleaginosas-para-a-producao-de-bioquerosene-oportunidades-e-desafios> Acesso em: 20 março 2016.

OETTERER, M.; REGITANO-D'ARCE, M.A.B.; SPOTO, M.H. Fundamentos de Ciência e Tecnologia de Alimentos. São Paulo: Ed. Manole, 2006.

OLISUL. Situação de Mercado. Disponível em: < http://www.oliviculturars.com.br/situacao_mercado.html> Acesso em: 22 março 2016.

SUAREZ, P. A. Z. et al. Extração de óleo de mamona utilizando etanol em extrator semicontínuo. In: $33^{\circ}$ Reunião Anual da SBQ, 2009.

TAWARAH, K. M.; RABABAH, R. A. Characterization of Some Jordanian Crude and Exhausted Olive Pomace Samples. Green and Sustainable Chemistry, 2013, v.3, p.146162. 